\title{
AS DIMENSÕES DO UNIVERSO POÉTICO DE LINEAR G, DE GILBERTO MENDONÇA TELES
}

\author{
Ilca Vieira de OLIVEIRA ${ }^{117}$
}

TELES, G. M. Linear G. São Paulo: Hedra, 2010.
Não há poesia fora do nome e do ser que o condensa e o contorna silencioso.
Até o timbre de uma sílaba me excita à sensação da trajetória interior. (TELES, 2003, p.186).

Linear $G$ é o mais recente livro de poesia publicado por Gilberto Mendonça Teles. Em outubro de 2010, duas caixas de livros chegaram à casa desse poeta ${ }^{118}$. Vejase a estrofe a seguir: "Durante anos - mais de 60 - foi alimentando / a ilusão de uma biblioteca de 30 mil volumes / Ele queria possuir todos os livros / de literatura brasileira." (TELES, 2010, p. 42) O poeta irá recriar, poeticamente, a chegada de livros à casa de um professor de literatura. Esses versos da primeira estrofe do poema "Biblioteca" expressam a angústia do colecionador e, também, do sujeito que "queria possuir todos os livros / de literatura brasileira”.

$\mathrm{Na}$ voz do eu lírico que se projeta no poema, surge a imagem de um sujeito que passou décadas recebendo "livros dos editores e dos jovens escritores", comprando-os e lendo-os. Se, por um lado, tem-se alguém que deseja ler todos os livros e os adquiriu pelo prazer da leitura e de colecioná-los, por outro, esse sujeito perde o interesse pela leitura, como expõe com os versos: "E lia, lia, mas já sem muito entusiasmo / Sentia-se

117 Departamento de Comunicação e Letras, Programa de Pós-Graduação (Mestrado) em Letras (Estudos Literários), Centro de Ciências Humanas, Universidade Estadual de Montes Claros, UNIMONTES, CEP 39401-089, Montes Claros, MG, Brasil - ilca.vieira@pq.cnpq.br / ilcavieiradeoliveira@yhaoo.com.br

118 No dia 21 de outubro de 2010, eu estava na casa de Gilberto, em Copacabana, quando duas caixas de livros foram entregues pelos Correios. No mesmo dia eu recebi o primeiro exemplar desse livro com uma dedicatória. Naquela ocasião pude ter o prazer de ouvir o poeta lendo alguns poemas com comentários. Lembro-me até hoje da leitura e dos comentários que ele fizera sobre o poema "Encontro", em que o poeta pede ao pai a alegria de um encontro. 
menor que os livros". Para superar essa angústia de alguém que era "menor que os livros", esse sujeito tem a ideia genial de empacotá-los e "devolvê-los aos seus autores". No poema, é possível perceber a intenção do poeta de enfatizar, no jogo da linguagem, a sua própria experiência de vida como professor de literatura brasileira que se transforma em um leitor compulsivo e, também, o ofício de escritor crítico, teórico e poeta que atua no cenário nacional e internacional. O poema revela o que está implícito: a grande realização desse poeta que irá publicar os seus próprios livros, passando "a devolvêlos”. Esse livro de capa vermelha e sem ácaros não ficará por muito tempo no espaço habitado pelo poeta, porque não é um volume que é adquirido para fazer parte da casa e da biblioteca desse colecionador, mas é um objeto que proporcionará ao escritor libertar-se da angústia de querer ler todos os livros.

O poeta abre o seu livro com uma citação de dois textos que ajudará o leitor a “decifrar" o próprio título "Linear G". O primeiro texto expõe uma definição para o "G" que seria: " - Antes de mais nada invoco a [Terra $=G$ (gue)], primeira que tem o dom de conhecer antecipadamente. PITONISA DE DELFOS, apud As eumênides, DE ÉSQUILO” (TELES, 2010, p. 5). E o segundo é uma possível definição para o que seria a escrita "linear": - A Linear A, que aparece por volta de 1600 a.C. é formada de signos mais abstratos. - A Linear B, escrita silábica, origina-se formalmente da anterior, sem que se possa precisar a data de sua aparição. [...] Desapareceu em torno de 1400 a.C. LOUIS-JEAN CALVET”. (TELES, 2010, p. 5)

No entanto, é importante destacar que, já na primeira epígrafe, o "T" da terra que, por sua vez, pode ser lido como uma abreviação de Teles, nome que faz parte da árvore genealógica do poeta - pode ser lido também como "G" de Gilberto, GO de Goiás, de Grécia, de Geometria euclidiana, riemanniana, fractal e, também, como o $\Gamma, \gamma$ (gama). Como se pode ver, esse poeta se coloca no centro do "tempo e do espaço". Se considerarmos tal aspecto, é possível afirmar que "GMT" é o centro de toda a poesia, tendo, então, uma poética centrada no eu de cunho autobiográfico. O poema "Entre" é um texto que abre o livro e que nos permite relacioná-lo à voz do "Oráculo de Delfos", o qual convida o leitor a entrar na origem dessa poética do "G", ou seja, poética do "T". O que será anunciado na primeira estrofe é que: "Entre a esquerda e a direita,/ as ucronias / e as eutopias do cerrado - uma árvore / crescendo para dentro, o entressonhado, / o entrelugar do novo, o entressentido, / o entrevisto no escuro / - a sua face / e equilíbrio no caos incandescente". (TELES, 2010, p. 13) 
O verso: "Entre a esquerda e a direita" cria uma possibilidade de leitura dessa poética da Terra que tem o seu ponto de partida no grau zero. O sentido desse verso terá o seu complemento nos outros que irão sucedê-lo, em que o poeta faz alusão aos dois lados da terra, a "esquerda" e a "direita". "Greenwich Meridian Time”, de Saciologia Goiana, de 1982, é um poema em forma de triângulo em que o poeta escreve a sigla GMT em um dos ângulos dessa figura geométrica, utilizando esse meridiano para fazer uma reflexão sobre o seu nome. Cabe, aqui, ressaltar que é nesse poema que o poeta analogicamente compara o seu nome com o próprio meridiano, que é abreviado como GMT. Esse meridiano é uma linha imaginária que vai do polo norte ao polo sul, marcando o grau zero da Terra. É a partir desse ponto que todas as outras linhas de longitude são medidas. E, se considerarmos que o poeta se coloca no centro da Terra como Greenwich Meridian Time, o que existe à direita dessa linha imaginária da Terra são "as ucronias", que representam a tradição grega, e, à sua esquerda, "as eutopias do cerrado". O poeta, que se coloca no centro da terra e do universo, aparece também nos poemas "Mapa-mundi", "Fractal", "Cavalo-marinho" e "Navegando", da série Improvisuais [Inéditos], publicados em Hora aberta.

Com isso, o que podemos afirmar é que, apesar de o poeta dividir o livro em três partes, a saber: "As Ucronias", “As eutopias" e "Árvores do cerrado", o que fica evidente é que sua poesia se divide em duas linhas A, e B, sendo a linha A "as ucronias" e, a B, "eutopias do cerrado". A terra natal, Goiás, é o lugar em que o eu realiza os seus sonhos e fantasias eróticas e amorosas. É no seio dessa terra-mãe que o poeta irá encontrar a sua própria “identidade” fragmentada na sociedade moderna. Mas, Goiás só irá fazer parte de sua escrita poética a partir do momento em que esse poeta sai de seu lugar de origem e passa a viajar pelo mundo e a residir no Rio de Janeiro e em outros países, fatos notados em poemas escritos a partir de 1970.

Quando o poeta divide o seu livro em três partes, parece sugerir a possibilidade de se ver a Terra a partir de três dimensões, e isso seria uma alusão à teoria euclidiana. Entretanto, o que de fato se pode evidenciar é que, na poesia de Gilberto Mendonça Teles, existem dimensões que estão escondidas, pois o que o poema revela fisicamente estaria num universo muito maior de sua obra poética. É preciso que o leitor entre no poema e use o seu "Binóculo" para ver as coisas de perto e de longe, no universo poético desse livro.

Em Linear $G$, tem-se uma poesia centrada no "eu", com várias dimensões escondidas. Assim, é mais viável apontarmos que a teoria da relatividade é mais 
propícia para se pensar essa poética da Terra. Nesse sentido, o leitor não poderá considerar que esse livro apresente somente essas três dimensões visíveis, pois, dentro da poesia de Gilberto Mendonça Teles, há outras "dimensões escondidas", tais como: a amorosa, a melancólica, a saudosista, a erótica, a memorialística, a religiosa, a mítica e a metalinguística. Esses temas são recorrentes não só nesse último livro desse poeta, mas em todo o universo de sua poesia. Nesse universo da linguagem imagética, o poeta tenta organizar o caos interior, propiciando que a palavra poética construa um sujeito: "Na da atualidade, descentrado / mas concentrado no hic et nunc, / o sujeito se sente livre e fragmentado / na confusão do baile funk." (TELES, 2010, 38)

Um aspecto marcante desse livro, e que se encontra em toda a produção do autor, é o lugar que o poeta ocupa no mundo das letras. E o poema passa a ser espaço de indagação e de discussão sobre o ofício do poeta e a sua liberdade de ser e existir. Em vários poemas, o eu lírico, conjuga no esqueleto "rígido das estruturas" da língua, o exercício mental, os aspectos pessoais de cunho didático. A poesia que brota dessa "árvore do cerrado" instiga o leitor a conhecer o mundo e a sua relatividade. O poeta é um sujeito letrado que se apropria de uma tradição grega, exercendo o seu ofício de poetar com a perfeição dos antigos, mas é capaz de reconhecer as modificações pelas quais passou a sociedade.

O poeta é aquele que acompanha as transformações sociais, culturais, estéticas e tecnológicas do mundo, aspecto que é recriado no poema "Nos últimos 20 anos". Esse poema apresenta a imagem da "lagarta" e da "aranha"; esses dois bichos vão, metaforicamente, representar o tempo passado e presente, com suas transformações. O poeta faz alusão à sua própria experiência de vida e à sua inserção no mundo da internet, nesta estrofe: "Entre greves, censura e terrorismo / um relâmpago veio da internet, / riscou seu movimento, abriu um site / e se perdeu na pós-modernidade / do milênio." (TELES, 2010, p. 17).

A imagem da "lagarta" que come "o talo verde/ de uma folha esculpida na parede / do edifício mais próximo" pode ser lida como o próprio poeta a "devorar todas as folhas dos autores gregos" e que sai do seu casulo na forma de "borboleta". Esse pequeno inseto pode ser interpretado como a poesia que é efêmera e breve. Nos versos da estrofe: "Uma aranha / teceu e desteceu a sua renda / à espera da odisseia de um inseto / curioso". (TELES, 2010, p. 17) O poeta recupera, mesmo que implicitamente, as personagens Ulisses e Penélope, da Odisseia. E a mulher é um ser ardiloso como a "aranha que tece", "destece" os fios das rendas, precisamente do tempo, enquanto o 
homem estava em suas viagens. Se o poeta é esse inseto que é apreendido pela "teia da aranha", é possível considerar o poeta como uma "aranha" à espera de um inseto, ou seja, é aquele que tece ardilosamente o seu poema para "apreender", em suas teias, um crítico "curioso".

O poeta não é representado somente como uma "aranha", mas como o engenheiro, que para construir a sua "casa-poema", não irá se esquecer das "estruturas subterrâneas" que são as suas fundações. Nesse caso, a poesia grega representa essas estruturas. O poema, objeto que emerge da linguagem, pode ser comparado a uma "árvore", ou seja, um "vegetal lenhoso" que brota do centro da terra, composto por raízes, tronco, galhos e folhas. Logo no início do livro, vemos, no poema "Entre", surgir a imagem da "árvore do cerrado", como representante de uma linha que está à esquerda do meridiano GMT. Essa imagem será retomada pelo poeta com a indicação da "árvore" como representante da obra poética, crítica e teórica presente no poema "Pau-terra". Esse poema é utilizado para abrir a terceira parte do livro e é estruturado em forma de árvore, cujo tronco é constituído de palavras escritas na língua grega, com os galhos sendo representados por todos os nomes dos livros de poesia e de estudos críticos e teóricos elaborados por esse escritor ao longo de mais de 50 anos de labor.

Significativamente, eis a origem da poética de Gilberto Mendonça Teles, pois o poeta indica, com esse livro, uma abertura para se ler toda a sua produção poética, ao criar, para o seu leitor, um "sistema linear". Não é de se estranhar o fato de esse poeta utilizar como título desse livro de sua maturidade a palavra "linear", termo da matemática, já que, em vários momentos de sua poesia, existe um diálogo com a linguagem da geometria, principalmente quando ele se apropria da geometria euclidiana. As figuras, as letras e os símbolos gregos foram utilizados por Gilberto para dar título ao livro que recebe o nome de \& Cone de sombras, e na construção de poemas visuais e dos sentidos. Citamos as letras $(\alpha)$ alfa, $\Gamma, \gamma$ (gama), os símbolos o $\Delta$ (delta), o

(nabla), o $\Phi$ (phi), o \&, e as figuras geométricas o cone, o losango e o triângulo equilátero. Ao criar o título para esse livro, o poeta faz um jogo, pois o sistema linear é uma representação algébrica da geometria euclidiana e, ao invés de dizer "Geometria", ele diz "Linear G". Diante disso, podemos inferir que há um poeta em busca da "perfeição" - própria dos gregos que se destacaram não só na literatura, mas na filosofia, nas ciências, nas artes da guerra e do amor - e que a sua poesia poderia ser 
pensada a partir da geometria euclidiana, ou seja, essa poética estaria para o abstrato, o subjetivo e o infinito ${ }^{119}$.

Nesse livro a linear A, que "é formada de signos mais abstratos", representa "as ucronias", ou seja, toda a tradição da lírica grega que servirá de fundação para essa poesia do "T", ou mais precisamente, poética do "G". Esse livro encena uma escrita de si no qual o nome "G" existe a partir das experiências vividas e reinventadas pelo poeta que evoca as suas musas. O poeta se inscreve no espaço da casa, com a família e um casamento com "bodas de ouro", como expõe no poema "Receita dos 50 anos (de casado)". Nesse processo de escrita autobiográfica e memorialística, o poeta já começa a acertar as suas contas com o passado, à maneira do seu mestre Drummond, quando revela, no poema "Encontro", uma reconciliação com o pai que parecia distante, mas que o amava.

Entrei pelas fendas desse livro e ainda estou procurando a saída. E o que já posso adiantar ao leitor é que é preciso ter não só binóculo, mas microscópio e telescópio para poder percorrer essa escrita da " $T=G$ (gue)". Esse poeta não é um sujeito ingênuo que foi seduzido pelas musas do sertão, pois, quando recria a sua terra natal, expõe uma linguagem ardilosa como o tecido feito pela aranha. Expõe, também, a figura do Saci, tão bem representada em sua poética e que não pode ser esquecida, pois o poeta é o Saci que sai "Navegando" no universo atrás da Ursa Maior.

\section{REFERÊNCIAS}

ANTON, H.; RORRES, C. Álgebra linear com aplicações. Tradução de Claus Ivo Doering. 8.ed. Porto Alegre: Bookman, 2001.

PAIVA, M. Matemática. São Paulo: Moderna, 1999.

TELES, G. M. Linear G. São Paulo: Hedra, 2010.

\& Cone de Sombras. In:

Petrópolis, RJ: Vozes, 2003. p.175-257.

. Hora aberta (Poemas reunidos). 4.ed. Improvisuais [Inéditos]. In:

Hora aberta (Poemas reunidos). 4.ed. Petrópolis, RJ: Vozes, 2003. p.75-86. . Saciologia goiana [1982]. In: Hora aberta (Poemas reunidos). 4.ed. Petrópolis, RJ: Vozes, 2003.

119Para discutir esses conceitos expostos sobre sistema linear e geometria obtive o auxílio de especialistas na área que são Antônio Geraldo de Oliveira (Professor da rede de ensino do Estado de Minas Gerais) e Sebastião Alves de Souza (Professor na UNIMONTES) e também pesquisei em alguns livros de matemática e de álgebra linear. 